\title{
Influence of thermophysiology on thermal behavior: the essentials of categorization
}

Citation for published version (APA):

Jacquot, C., Schellen, L., Kingma, B. R., van Baak, M. A., \& van Marken Lichtenbelt, W. D. (2014).

Influence of thermophysiology on thermal behavior: the essentials of categorization. Physiology \&

Behavior, 128, 180-187. https://doi.org/10.1016/j.physbeh.2014.01.025

Document status and date:

Published: 10/04/2014

DOI:

10.1016/j.physbeh.2014.01.025

Document Version:

Publisher's PDF, also known as Version of record

Document license:

Taverne

Please check the document version of this publication:

- A submitted manuscript is the version of the article upon submission and before peer-review. There can be important differences between the submitted version and the official published version of record.

People interested in the research are advised to contact the author for the final version of the publication, or visit the DOI to the publisher's website.

- The final author version and the galley proof are versions of the publication after peer review.

- The final published version features the final layout of the paper including the volume, issue and page numbers.

Link to publication

\footnotetext{
General rights rights.

- You may freely distribute the URL identifying the publication in the public portal. please follow below link for the End User Agreement:

www.umlib.nl/taverne-license

Take down policy

If you believe that this document breaches copyright please contact us at:

repository@maastrichtuniversity.nl

providing details and we will investigate your claim.
}

Copyright and moral rights for the publications made accessible in the public portal are retained by the authors and/or other copyright owners and it is a condition of accessing publications that users recognise and abide by the legal requirements associated with these

- Users may download and print one copy of any publication from the public portal for the purpose of private study or research.

- You may not further distribute the material or use it for any profit-making activity or commercial gain

If the publication is distributed under the terms of Article $25 \mathrm{fa}$ of the Dutch Copyright Act, indicated by the "Taverne" license above, 


\title{
Influence of thermophysiology on thermal behavior: the essentials of categorization
}

\author{
Christel M.C. Jacquot ${ }^{\mathrm{a}}$, Lisje Schellen ${ }^{\mathrm{a}, \mathrm{b}}$, Boris R. Kingma ${ }^{\mathrm{a}}$, \\ Marleen A. van Baak ${ }^{a}$, Wouter D. van Marken Lichtenbelt ${ }^{\mathrm{a}, *}$ \\ a Department of Human Biology, NUTRIM School for Nutrition, Toxicology and Metabolism of Maastricht University Medical Center+, P.0. Box 616, 6200 MD Maastricht, The Netherlands \\ b School of Built Environment and Infrastructure, Avans University of Applied Sciences, P.O. Box 1097, 5004 BB Tilburg, The Netherlands
}

\section{H I G H L I G H T S}

- Categorization improves the prediction of thermal sensation from skin temperatures.

- Head, underarm, chest and wrist temperatures are correlated with thermal sensation.

- Thermal sensation is highly correlated with thermal preference.

\section{A R T I C L E I N F O}

\section{Article history:}

Received 1 August 2013

Received in revised form 13 December 2013

Accepted 26 January 2014

Available online 8 February 2014

\section{Keywords:}

Thermoregulatory behavior

Thermophysiology

Categorization

Thermal sensation

Thermal preference

\begin{abstract}
A B S T R A C T
Predicted energy use of dwellings often deviates from the actual energy use. Thermoregulatory behavior of the occupant might explain this difference. Such behavior is influenced by thermal sensation and thermal comfort. These subjective ratings in turn are linked to physiological parameters such as core and skin temperatures. However, it is unclear which physiological parameters best predict thermoregulatory behavior.

The objective of this research was to study physiological parameters that potentially can be used to predict thermoregulatory behavior. Sixteen healthy females (18-30 years) were exposed to two dynamic temperature protocols: a gradual increase $\left(+4 \mathrm{~K} / \mathrm{h}\right.$, ranging from $24^{\circ} \mathrm{C}$ to $\left.32{ }^{\circ} \mathrm{C}\right)$ and a gradual decrease in ambient temperature $\left(-4 \mathrm{~K} / \mathrm{h}\right.$, ranging from $24^{\circ} \mathrm{C}$ to $\left.16{ }^{\circ} \mathrm{C}\right)$. During the experiments physiological responses, thermal sensation, thermal preference and the intention of thermoregulatory behavior were measured. Thermal sensation is highly correlated with thermal preference $(\mathrm{r}=-0.933, \mathrm{P}<0.001)$. The skin temperature of the wrist best predicts thermal sensation $\left(\mathrm{R}^{2}=0.558, \mathrm{P}<0.001\right)$ and therefore seems useful as a physiological parameter to predict the intention of thermoregulatory behavior. When the subjects are categorized based on their thermal sensation votes, more precise predictions of thermal sensation can be made. This categorization therefore can be of value for the determination of the actual energy use of occupant in dwellings.
\end{abstract}

(c) 2014 Elsevier Inc. All rights reserved.

\section{Introduction}

Predictions of the energy consumption of dwellings and related potential energy savings are a necessity in the built environment. However, the actual energy use of dwellings often deviates from the energy use predicted [1-3]. Thermoregulatory behavior of the occupant might explain this difference $[1,4,5]$. To make more realistic predictions of energy consumption in the built environment, a prediction of the thermoregulatory behavior of occupants is needed.

Thermoregulatory behavior is an important response in conjunction with autonomic responses [6]. Moving from one environment to another, avoiding the sun, changing clothes and adjusting the thermostat are

\footnotetext{
* Corresponding author. Tel.: +31433881629.

E-mail address: markenlichtenbelt@maastrichtuniversity.n (W.D. van Marken Lichtenbelt)
}

all examples of thermoregulatory behavior. These actions are initiated to avoid thermal discomfort or displeasure, and obtain thermal pleasure [7]. However, relatively little is known about which physiological parameters drive thermoregulatory behavior.

Thermoregulatory behavior is influenced by changes in thermal sensation and thermal comfort [8,9]. Thermal sensation can be described as the subjective evaluation of a conscious feeling such as being warm or cold $[10,11]$. Thermal comfort is the state of mind that expresses satisfaction with the surrounding environment $[10,11]$. Moreover, several studies indicate that an acceptable thermal environment for general comfort is linked to thermal sensation limits. This phenomenon is described by the standard predicted mean vote model (PMV-model) with a seven-point thermal sensation scale ranging from -3 to 3 . Thermal sensation ranging between -0.5 and 0.5 is considered as acceptable $[11,12]$. Thermal sensation and thermal comfort in turn are determined for a large part by physiological parameters, such 
as core and skin temperatures [9,13-17]. Wang et al. [14], for example, found that thermal sensation is correlated to finger temperature and the temperature gradient between the finger and the forearm. However, regarding thermoregulatory behavior it is unclear which physiological parameters are most influential in predicting this behavior. Deviations in skin temperature from the thermoneutral level can cause thermal discomfort, which is a stimulus or input for thermoregulatory behavior $[9,18,19]$. Therefore, skin temperature may be a potential parameter regarding the prediction of thermal behavior.

Between subpopulations differences exist in thermal perception and therefore probably in thermoregulatory behavior as well. In females, thermal dissatisfaction is more often expressed than in males [20-23]. Furthermore, females seem to be more sensitive than males to a deviation of the temperature from thermoneutrality [24]. When the ambient temperature changes, females might show changes in thermoregulatory behavior sooner compared to men. Moreover, until now most studies on thermoregulatory behavior are performed in males. Therefore, females are an interesting subpopulation to examine the physiological parameters that lead to thermal discomfort and consequently to changes in thermoregulatory behavior.

The objective of this study was to examine in females those physiological parameters that can be used to predict the intention of thermoregulatory behavior under dynamic thermal conditions. Furthermore, the underlying mechanisms and the influence of thermophysiology, e.g. body temperatures, on thermoregulation were studied. The results indicate that categorization of the subjects based on thermal sensation votes improves the prediction of the intention of thermoregulatory behavior.

\section{Methods}

\subsection{Subjects}

Sixteen healthy, female subjects (18-30 years) participated in the study; their characteristics are presented in Table 1. All subjects were studied between May and August 2012. They were taking oral contraceptives and were not measured during their menstruation period to standardize hormonal effects on thermoregulation $[25,26]$. The volunteers were given detailed information regarding the purpose and the methods used in the study, before written informed consent was obtained. The protocol was approved by the ethics committee of Maastricht University Medical Center+ and performed according to the Declaration of Helsinki.

\subsection{Experimental protocol}

Each subject completed two experimental protocols in randomized order (protocols A and B), which are presented in Fig. 1. In all protocols ambient temperature was set at $24{ }^{\circ} \mathrm{C}$ during the first $45 \mathrm{~min}$, which served as baseline measurement. Ambient temperature increased with $4 \mathrm{~K} / \mathrm{h}$ to $32{ }^{\circ} \mathrm{C}$ in protocol $\mathrm{A}$. In protocol $\mathrm{B}$, ambient temperature decreased with $4 \mathrm{~K} / \mathrm{h}$ to $16{ }^{\circ} \mathrm{C}$.

Subjects arrived at the laboratory after overnight fasting and having refrained from alcohol and caffeine for a period of $10 \mathrm{~h}$. To minimize the influence of hunger on the responses to the questionnaire, subjects

Table 1

Subject characteristics.

\begin{tabular}{lc}
\hline & Mean \pm SD \\
\hline Age $($ year $)$ & $23 \pm 4$ \\
Height $(\mathrm{m})$ & $1.69 \pm 0.06$ \\
Body mass $(\mathrm{kg})$ & $65.5 \pm 7.9$ \\
BMI $\left(\mathrm{kg} / \mathrm{m}^{2}\right)$ & $22.9 \pm 1.9$ \\
Body fat $(\%)$ & $28.2 \pm 5.5$ \\
Muscle mass $(\mathrm{kg})$ & $44.7 \pm 3.8$ \\
Body surface area $\left(\mathrm{m}^{2}\right)$ & $1.88 \pm 0.56$ \\
\hline
\end{tabular}
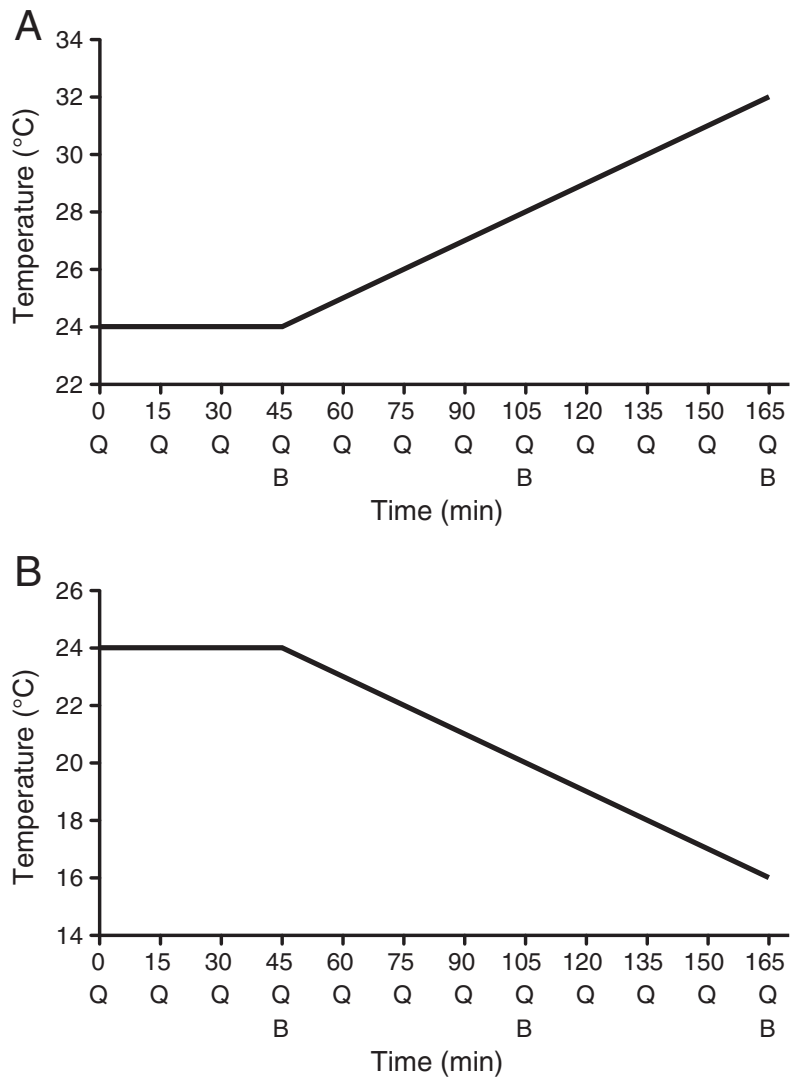

Fig. 1. Timelines of the two experimental protocols: (A) protocol A and (B) protocol B. Q represents the questionnaires that were being filled in, B represents the blood collection.

were allowed to eat a small breakfast (one sandwich, 180 kcal). Furthermore, they were instructed to eat a weighed amount of biscuits ( $40 \mathrm{kcal} / 30 \mathrm{~min}$ ) according to their weight, height and age, calculated with the Harris-Benedict formula and multiplied by an estimated physical activity level of 1.3 to maintain energy balance [27]. They were allowed to drink lukewarm water at libitum.

After arrival at the laboratory, a catheter was inserted in a forearm vein of the subject for blood sampling, a telemetric pill was ingested and iButtons, a pressure cuff to measure blood pressure and a chest strap to measure heart rate were attached. Subsequently, the subject took place on an office chair behind a desk in a climate-controlled respiration chamber. Total preparation time was approximately $45 \mathrm{~min}$. After preparation, protocol A or B started (Fig. 1).

Each trial was completed within four months, and each subject completed both protocols within one month, with at least one day between the protocols. The subjects wore standardized clothing; underwear, cotton/polyester sweatpants, a pair of sport socks and a cotton T-shirt $(0.58 \mathrm{Clo})$, sat on a standard office chair $(0.1 \mathrm{Clo})$ and were allowed to do deskwork (1.2 METs) [28].

\subsection{Experimental procedures}

\subsubsection{Anthropometric measurements}

The subjects' height and weight were measured using a stadiometer (Seca, Germany) and scale (Mettler-Toledo, Germany), respectively, from which BMI was calculated. Body composition was determined by means of a DXA-scan (Discovery A, Hologic Inc., USA). Body surface area was calculated using heights and circumferences (Seca, Germany) of the different body components and limbs (head, neck, chest, abdomen, bottom and from the right sight of the body the upper arm, lower arm, hand, upper leg, lower leg and foot). 


\subsubsection{Physical and physiological temperature measurements}

Ambient temperature and relative humidity were measured at 1 min intervals using iButtons (DS1923, Maxim, USA), at $0.7 \mathrm{~m}$ and $1.1 \mathrm{~m}$ height. Core temperature was determined at $1 \mathrm{~min}$ intervals using an ingestible telemetric pill (Core Body Temperature Sensor HT150002, CorTemp, HQ Inc, USA). Skin temperature was measured at 1 min intervals using iButtons (DS1922L, Maxim, USA), placed on 14 sites on the body as prescribed by the ISO 9886 standard [29] with two additional buttons placed at the under arm and the middle finger. iButtons were attached with semi-permeable adhesive tape (Fixomull, BSN Medical, Germany). Mean skin temperature was calculated as average of the 14 positions, proximal skin temperature was calculated as average of chest, abdomen, shoulder and lower back skin temperatures. Distal skin temperature was calculated as average of wrist and foot skin temperatures.

\subsubsection{Subjective measurements}

Every 15 min the subjects filled in a questionnaire. Thermal sensation was measured on a continuous seven-point ASHRAE thermal sensation interval scale, which ranged from -3 cold to 3 hot [11]. Thermal comfort was assessed using a continuous four-point scale, which ranged from very uncomfortable $(-2)$ to very comfortable $(+2)$. The scale was split in two parts, which forced the subjects to determine whether their perceived state was "comfortable" or "uncomfortable" (Fig. 2A) [16]. Thermal preference was measured on a continuous seven-point interval scale, (Fig. 2B; from -3 , much cooler, to 3 , much warmer) [30]. The importance of changing temperature was measured on a continuous scale by asking, "how important is it to change?" (Fig. 2C; from 0, not important, to 10, important).

To assess acceptability of the environment the question was asked, "how do you perceive the thermal environment?" which could be answered with "acceptable" or "unacceptable". To assess the intention to change the ambient temperature (behavioral intention) a separate question was included; "do you want to change the temperature?" which could be answered with "yes" or "no". In order to obtain an indication about sweating and shivering a continuous four-point interval scale was used (Fig. 3; from no to yes). All questionnaires were webbased and presented in Dutch to the subjects.

\subsubsection{Blood analysis}

Per blood collection, $25 \mathrm{~mL}$ of blood was taken for the following analyses: plasma catecholamines, serum thyroid-stimulating hormone (TSH) and free thyroxin (fT4). Plasma catecholamines were determined using reagents from Recipe (Recipe, Germany) and analyzed by HPLC with electrochemical detection. TSH was measured by electrochemiluminescence immunoassay kit on a COBAS 6000 system (Roche Diagnostica). fT4 was

A

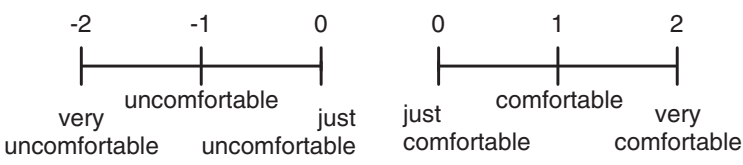

B

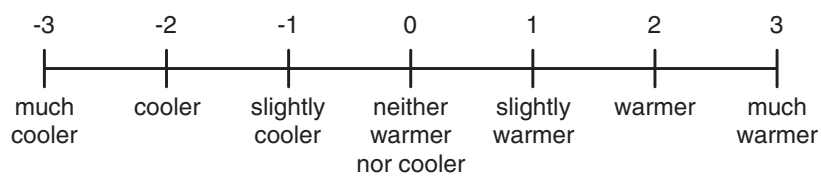

C 0

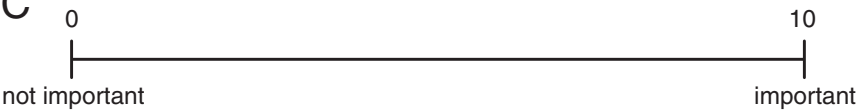

Fig. 2. Scales from the questionnaire: (A) four-point thermal comfort scale [16], (B) continuous seven-point thermal preference interval scale [30], and (C) continuous scale for the importance to change temperature.

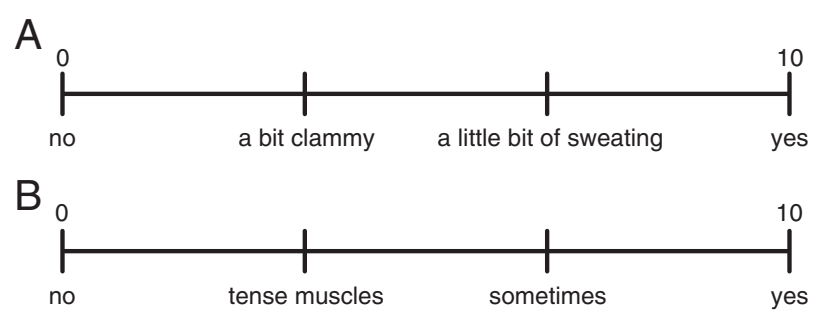

Fig. 3. Scales from the questionnaire: (A) continuous four-point sweating interval scale and (B) continuous four-point shivering interval scale.

analyzed by a solid-phase time-resolved fluoroimmunoassay fT4 kit on an AutoDELFIA system (PerkinElmer).

\subsection{Statistical analysis}

Mean, distal and proximal skin temperatures, core temperature, heart rate, thermal sensation, thermal preference, thermal comfort and importance of the preferred change were analyzed using a oneway repeated measures analysis of variance (ANOVA). The differences between the two protocols were tested with a paired sample $t$-test. Correlations between the different physiological parameters and the subjective measurements were tested with a Spearman ranked correlation. Stepwise regression analyses were used to study the relations between physiological parameters and thermal sensation. All data were analyzed using PASW Statistics 20.0 for Mac (SPSS, Chicago, IL). Data are reported as mean $\pm \mathrm{SD}$, and significant effects are reported for $\mathrm{P}<0.05$.

\section{Results}

\subsection{Physiological measurements}

Mean, distal and proximal skin temperatures significantly increased during protocol A (Table 2 and Fig. 4), and decreased significantly during protocol B (Table 3 and Fig. 4). Significant differences between A and $B$ were found from 30 min after the start of the gradual change in temperature onwards. No significant changes were found in core temperature, heart rate and blood pressure during both protocols $A$ and $B$ (Tables 2 and 3, Fig. 5). Furthermore, no significant difference in core temperature was measured between A and B (Fig. 5). Heart rate was significantly higher in protocol A compared to protocol B at the end of the trial.

\subsection{Blood parameters}

Thyroid hormones were within normal range; TSH: $1.8 \pm 1.0 \mathrm{mU} / \mathrm{L}$, T4: $12.4 \pm 1.7 \rho \mathrm{mol} / \mathrm{L}$. However, for one subject (subject 14) TSH was

Table 2

Ambient temperature, body temperatures, heart rate and blood pressure at the baseline $(T=0-45)$ and at the end $(T=165)$ for protocol $A$.

\begin{tabular}{|c|c|c|}
\hline & \multicolumn{2}{|l|}{ Protocol A } \\
\hline & Baseline $(\mathrm{T}=0-45)$ & End $(T=165)$ \\
\hline & $\overline{\text { Mean } \pm \text { SD }}$ & $\overline{\text { Mean } \pm \text { SD }}$ \\
\hline Ambient temperature $\left({ }^{\circ} \mathrm{C}\right)$ & $24.9 \pm 0.3$ & $32.6 \pm 0.6^{*}$ \\
\hline Mean skin temperature $\left({ }^{\circ} \mathrm{C}\right)$ & $33.2 \pm 0.5$ & $35.1 \pm 0.3^{*}$ \\
\hline Proximal temperature $\left({ }^{\circ} \mathrm{C}\right)$ & $34.3 \pm 0.5$ & $35.8 \pm 0.8^{*}$ \\
\hline Distal temperature $\left({ }^{\circ} \mathrm{C}\right)$ & $31.7 \pm 1.2$ & $33.8 \pm 1.9^{*}$ \\
\hline Core temperature $\left({ }^{\circ} \mathrm{C}\right)$ & $37.3 \pm 0.1$ & $37.4 \pm 0.2$ \\
\hline Heart rate $(\mathrm{bpm})$ & $80 \pm 9$ & $86 \pm 13$ \\
\hline Systolic blood pressure (mm Hg) & $111 \pm 9$ & $119 \pm 33$ \\
\hline Diastolic blood pressure ( $\mathrm{mm} \mathrm{Hg}$ ) & $72 \pm 8$ & $73 \pm 23$ \\
\hline
\end{tabular}

\footnotetext{
* Denotes a significant difference from the baseline $(\mathrm{T}=0-45)$ of the measurement
} (paired $t$-test, $\mathrm{P}<0.05$ ). 


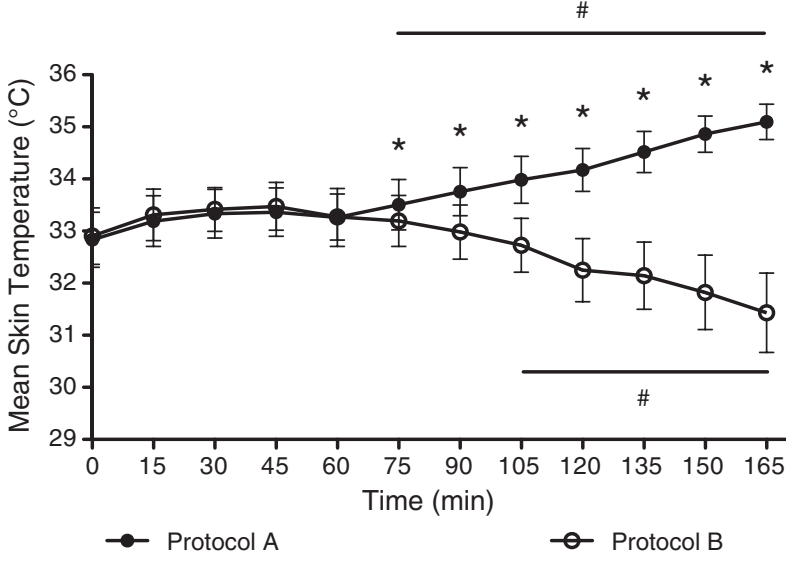

Fig. 4. Mean skin temperature during protocols $A$ and $B($ mean $\pm S D) .{ }^{*}$ denotes a significant difference between protocols $A$ and $B(P<0.05)$. \# denotes a significant difference with baseline condition $(\mathrm{T}=0-45, \mathrm{P}<0.05)$.

above normal level ( $4.9 \mathrm{mU} / \mathrm{L})$ and fT4 was normal. Plasma norepinephrine levels were similar at the start of both protocols $A$ and $B$. During protocol A norepinephrine levels did not change and were $602.7 \pm 146.6 \mathrm{ng} / \mathrm{L}$ at the start and $568.9 \pm 134.9 \mathrm{ng} / \mathrm{L}$ at the end. During protocol B norepinephrine levels increased significantly from $559.3 \pm$ $203.5 \mathrm{u} \mathrm{ng} / \mathrm{L}$ to $818 \pm 235.9 \mathrm{ng} / \mathrm{L}$ ( $\mathrm{P}<0.05$ ). Plasma epinephrine levels were analyzed but due to high variation coefficients $(>10 \%)$ these analysis could not be used.

\subsection{Subjective responses}

During protocol A, thermal sensation increased significantly and thermal comfort decreased significantly (Table 4 and Fig. 6). The subjects felt significantly warmer at the end of the protocol and the indicated sweating occurred. The number of subjects that assessed the thermal environment as acceptable started to decrease at $105 \mathrm{~min}$ and at the end 9 of the subjects still assessed the thermal environment as acceptable. During protocol B, thermal sensation and thermal comfort decreased significantly (Table 5 and Fig. 6). The mean rate of shivering intensity increased during protocol B. At the end three subjects indicated a vote at the shivering scale of "sometimes". The number of subjects that assessed the thermal environment as acceptable started to decrease from 135 min onwards and at the end of the protocol 13 of the subjects still assessed the thermal environment as acceptable. Thermal sensation differed significantly between protocols A and B, immediately after the gradual change in ambient temperature was initiated.

Table 3

Ambient temperature, body temperatures, heart rate and blood pressure at the baseline $(T=0-45)$ and at the end $(T=165)$ for protocol $B$.

\begin{tabular}{|c|c|c|}
\hline & \multicolumn{2}{|l|}{ Protocol B } \\
\hline & Baseline $(\mathrm{T}=0-45)$ & End $(\mathrm{T}=165)$ \\
\hline & Mean \pm SD & Mean \pm SD \\
\hline Ambient temperature $\left({ }^{\circ} \mathrm{C}\right)$ & $25.0 \pm 0.2$ & $17.8 \pm 1.8^{*}$ \\
\hline Mean skin temperature $\left({ }^{\circ} \mathrm{C}\right)$ & $33.3 \pm 0.5$ & $31.4 \pm 0.8^{*}$ \\
\hline Proximal temperature $\left({ }^{\circ} \mathrm{C}\right)$ & $34.3 \pm 0.4$ & $33.5 \pm 0.5^{*}$ \\
\hline Distal temperature $\left({ }^{\circ} \mathrm{C}\right)$ & $31.7 \pm 1.3$ & $27.2 \pm 1.6^{*}$ \\
\hline Core temperature $\left({ }^{\circ} \mathrm{C}\right)$ & $37.3 \pm 0.2$ & $37.5 \pm 0.2^{*}$ \\
\hline Heart rate $(\mathrm{bpm})$ & $76 \pm 11$ & $71 \pm 14$ \\
\hline Systolic blood pressure (mm Hg) & $113 \pm 9$ & $118 \pm 15$ \\
\hline Diastolic blood pressure $(\mathrm{mm} \mathrm{Hg})$ & $70 \pm 8$ & $70 \pm 8$ \\
\hline
\end{tabular}

* Denotes a significant difference from the baseline $(\mathrm{T}=0-45)$ of the measurement (paired $t$-test, $\mathrm{P}<0.05$ ).

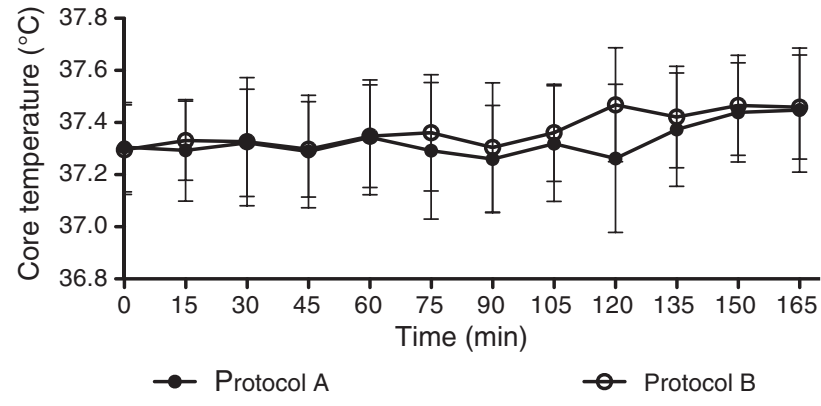

Fig. 5. Core temperature during protocols $A$ and $B($ mean $\pm S D)$.

\subsection{Behavioral intention}

The percentage of subjects that had the intention to change the ambient temperature (behavioral intention) increased during protocols $A$ and $B$ (Fig. 7). The importance to change the thermal environment increased significantly, both during protocols A and B (Fig. 6). The importance to change was larger at the end $(T=165)$ in protocol A compared to protocol B (Tables 4 and 5, Fig. 6). Thermal preference decreased significantly during protocol A and increased significantly during protocol $B$ (Tables 4 and 5, Fig. 6). Immediately after the gradual change in ambient temperature was initiated thermal preference differed significantly between protocols A and B (Fig. 6).

Thermal preference was significantly and highly correlated with thermal sensation $\left(R^{2}=0.908, p<0.001\right.$; Fig. 8$)$, e.g. when a subject indicated she was feeling slightly cool, she preferred to have it slightly warmer. Therefore, thermal sensation can be used as an indicator of thermoregulatory preference. When there was no behavioral intention to change ambient temperature, thermal sensation had a mean vote of -0.002 with a standard deviation of 0.544 . For the standard predicted mean vote-model (PMV-model), used in the built environment, a thermal sensation between -0.5 and 0.5 is considered acceptable $[11,12]$. This range, which is the acceptable thermal environment for general comfort, corresponds with the thermal sensation votes. Furthermore, the results revealed that for all subjects, when they requested a change, the comfort votes were in the discomfortable range. Mean overall comfort was $1.017 \pm 0.490$ for no intention to change and $-0.193 \pm$ 0.666 when there was an intention to change. There also exists a significant correlation between the intention to change and thermal comfort $(r=-0.736)$.

\subsection{Predicting thermoregulatory behavior}

As described above, thermal sensation can be used to give an indication of the intention of thermoregulatory behavior. Core temperature showed no correlation with thermal sensation $(r=-0.099)$. Temperatures on several sites of the skin were significantly correlated with

Table 4

Thermal sensation, thermal preference, thermal comfort, importance to change and sweating for protocol A.

\begin{tabular}{|c|c|c|}
\hline & \multicolumn{2}{|l|}{ Protocol A } \\
\hline & Baseline $(\mathrm{T}=0-45)$ & End $(T=165)$ \\
\hline & Mean \pm SD & Mean \pm SD \\
\hline Thermal sensation & $0.24 \pm 0.49$ & $2.14 \pm 0.59$ \\
\hline Thermal preference & $-0.27 \pm 0.42$ & $-2.12 \pm 0.72^{*}$ \\
\hline Thermal comfort & $0.99 \pm 0.5$ & $-0.62 \pm 0.89^{*}$ \\
\hline Importance to change & $1.21 \pm 1.36$ & $5.87 \pm 2.99^{*}$ \\
\hline Sweating & N.A. & $6.69 \pm 2.63$ \\
\hline
\end{tabular}
(paired $t$-test, $\mathrm{P}<0.05$ ). 


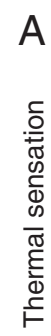

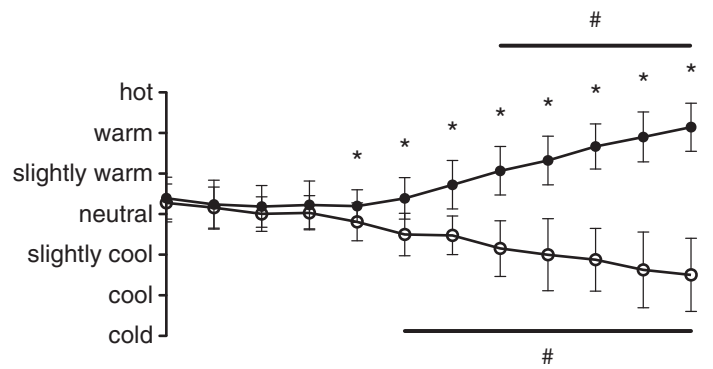

B
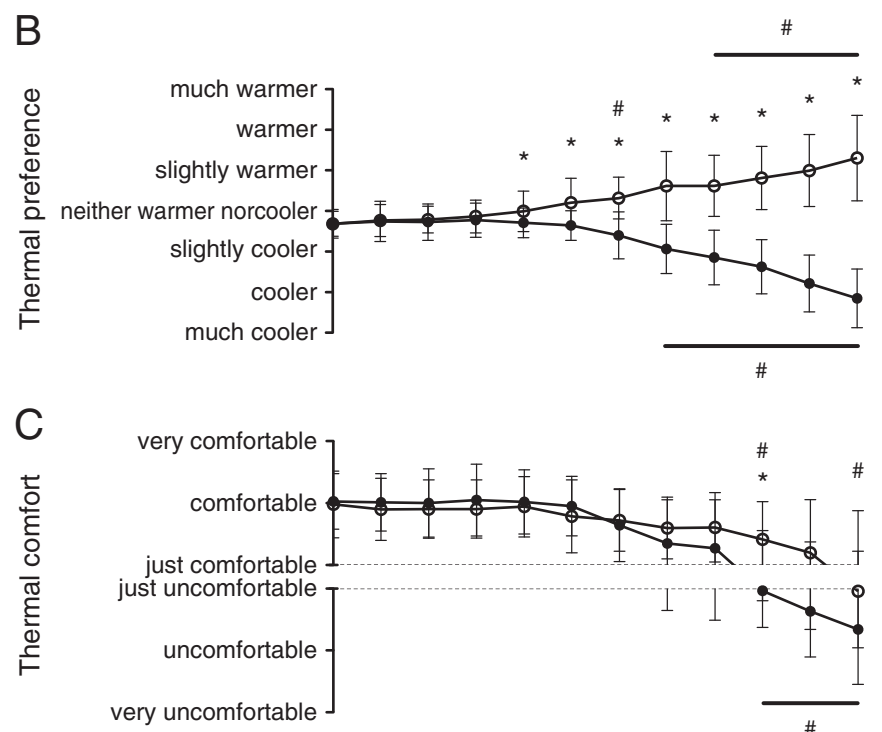

$\mathrm{D}$

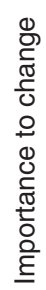

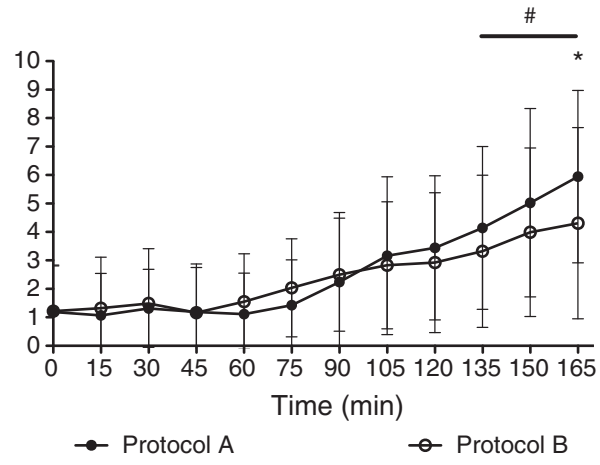

Fig. 6. (A) Thermal sensation, (B) thermal preference, (C) thermal comfort, and (D) the importance to change. All during protocols $A$ and $B($ mean $\pm S D) .{ }^{*}$ denotes a significant difference between protocols $A$ and $B(P<0.05)$. \# denotes a significant difference with baseline $(\mathrm{T}=0-45, \mathrm{P}<0.05)$.

\section{Table 5}

Thermal sensation, thermal preference, thermal comfort, importance to change and shivering for protocol $\mathrm{B}$.

\begin{tabular}{|c|c|c|}
\hline & \multicolumn{2}{|l|}{ Protocol B } \\
\hline & Baseline $(T=0-45)$ & End $(T=165)$ \\
\hline & Mean \pm SD & Mean \pm SD \\
\hline Thermal sensation & $0.12 \pm 0.39$ & $-1.49 \pm 0.91^{*}$ \\
\hline Thermal preference & $-0.22 \pm 0.31$ & $1.29 \pm 1.07^{*}$ \\
\hline Thermal comfort & $0.92 \pm 0.46$ & $-0.04 \pm 0.92^{*}$ \\
\hline Importance to change & $1.3 \pm 1.6$ & $4.3 \pm 3.37^{*}$ \\
\hline Shivering & N.A. & $2.74 \pm 2.74$ \\
\hline
\end{tabular}

\footnotetext{
* Denotes a significant difference from the baseline $(\mathrm{T}=0-45)$ of the measurement
} (paired $t$-test, $\mathrm{P}<0.05$ ).

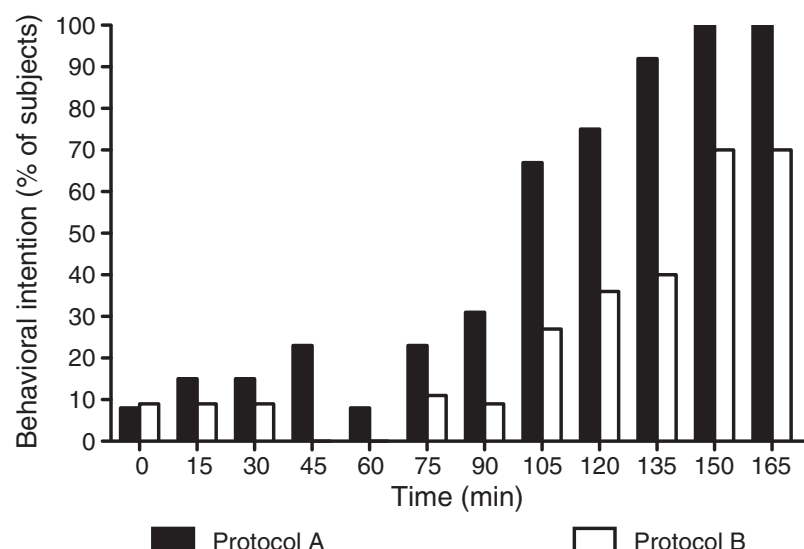

Fig. 7. Percentage of subjects that have the intention to change the ambient temperature (behavioral intention) at different time points during protocols $\mathrm{A}$ and $\mathrm{B}$.

thermal sensation (Table 6). The skin temperature of the wrist had the highest correlation coefficient with thermal sensation $(r=0.751$, $\mathrm{P}<0.001$; Table 6 and Fig. 9A) and therefore seems useful as a physiological parameter to predict the intention of thermoregulatory behavior. However, when only the skin temperature of the wrist is used, the predictive value of thermal sensation is still rather low $\left(R^{2}=0.558\right.$, Fig. 9A). To study the predictive value of a combination of skin temperatures, a stepwise regression analysis was conducted. Core temperature and skin temperature measured at 16 sites on the body were included in the analysis. Skin temperatures of the wrist, head, underarm and chest were retained in this order in the regression model as predictors of thermal sensation $\left(R^{2}=0.606, P<0.001\right)$. These skin temperatures together have a higher correlation $(\mathrm{r}=0.778, \mathrm{P}<0.001)$ with thermal sensation than skin temperature of the wrist alone.

\subsection{Subject categories}

Based on the thermal sensation votes of the individual subjects different categories with respect to thermal preference were distinguished.

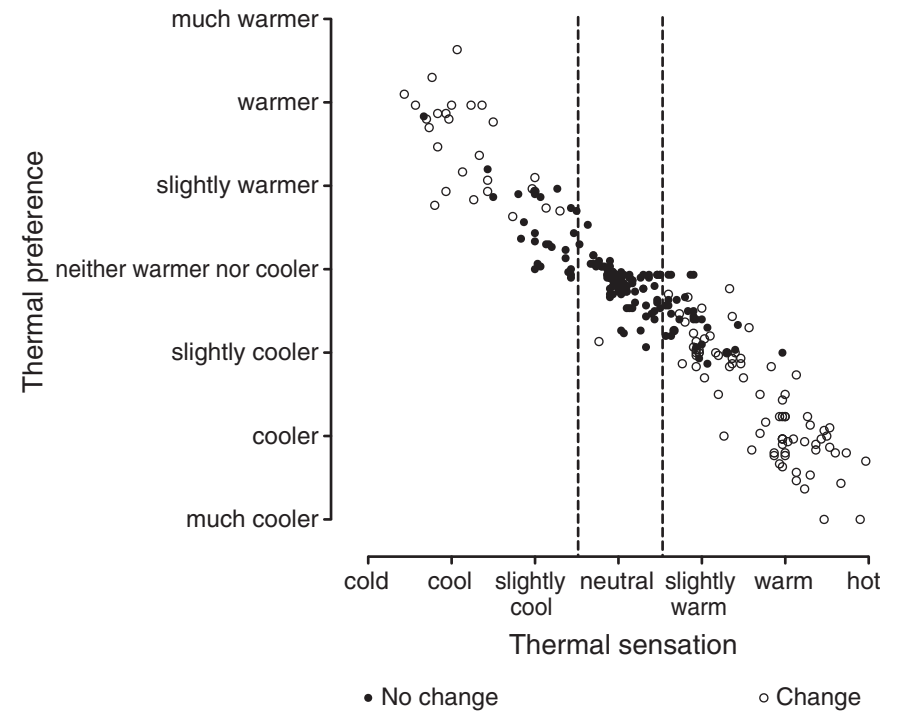

Fig. 8. Correlation between thermal sensation and thermal preference with the requested change as an indicator of actual behavior (open symbols: change, closed symbols: do not change, and dashed lines: boundaries of the PMV-model for an acceptable thermal environment for general comfort). 
Table 6

Relation of different skin temperatures with thermal sensation.

\begin{tabular}{lc}
\hline Skin temperature & Spearman correlation coefficient \\
\hline Head & 0.682 \\
Chest & 0.509 \\
Abdomen & 0.448 \\
Wrist & 0.751 \\
Upper leg (ventral) & 0.564 \\
Shin & 0.555 \\
Foot & 0.452 \\
Neck & 0.521 \\
Shoulder & 0.640 \\
Lower back & 0.437 \\
Upper leg (dorsal) & 0.298 \\
Calf & 0.401 \\
Upper arm & 0.654 \\
Elbow & 0.617 \\
Underarm & 0.675 \\
Finger & 0.726 \\
Underarm-finger difference & 0.352 \\
Distal & 0.657 \\
Proximal & 0.609 \\
\hline
\end{tabular}

Some individuals accepted larger temperature ranges than others, some preferred high temperatures, others low temperatures. When using the PMV neutral thermal sensation votes (ranging from -0.5 to 0.5 , Fig. 8 )
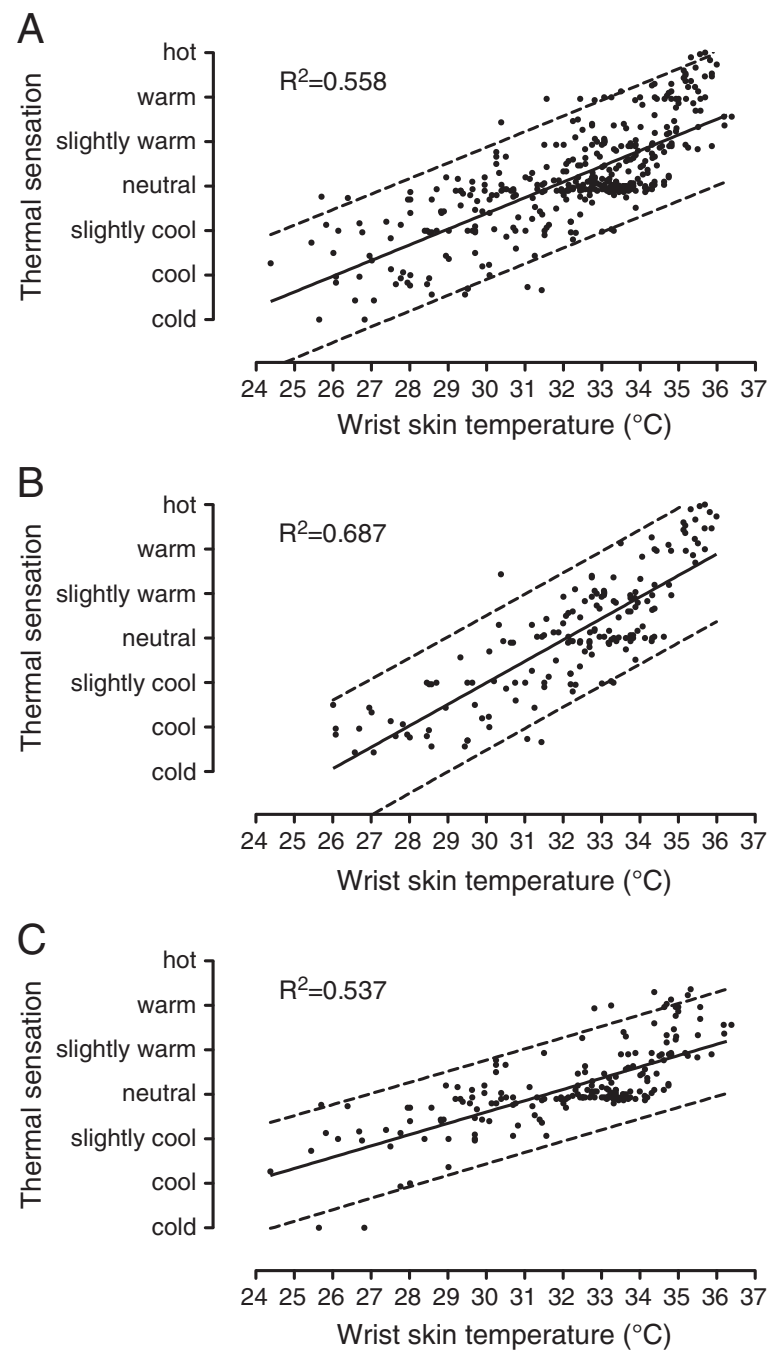

Fig. 9. Correlations between wrist skin temperature and thermal sensation with the regression line and the prediction intervals $(\mathrm{P}<0.001)$. A: for all the subjects together; $\mathrm{B}$ : after categorization representing small range preference subjects; and C: after categorization representing broad range preference B subjects.

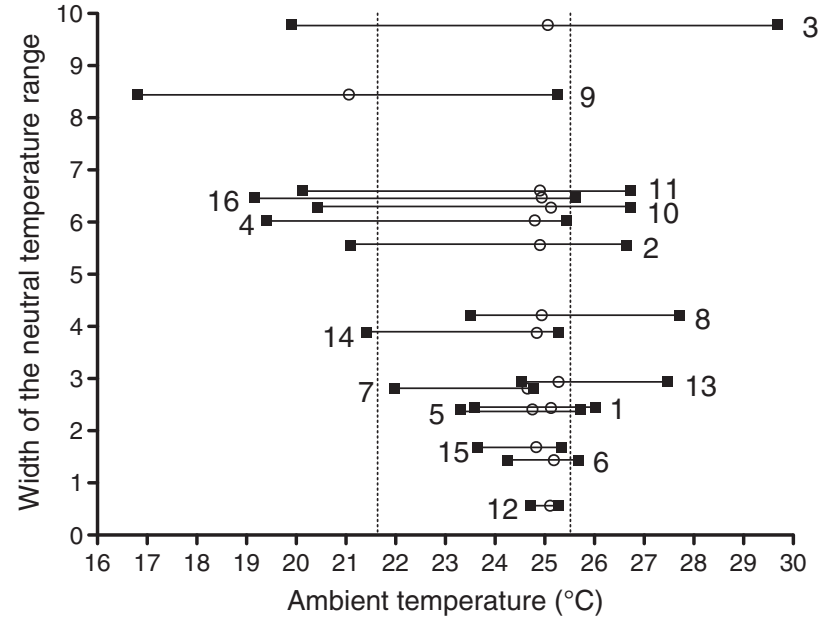

Fig. 10. Neutral ambient temperature range of the different test subjects (squares: limits of the neutral ambient temperature range, circles: median of the neutral ambient temperature range, and dashed lines: boundaries of the PMV-model for an acceptable thermal environment for general comfort).

as reference values in theory four categories can be distinguished, of which three were evident in this study (Fig. 10):

- Narrow range preference (subjects 1, 5, 6, 7, 12,13 and 15)

- Broad range preference (subjects 2, 3, 4, 8, 10,11, 14 and 16)

- Cool preference (subject 9)

- Warm preference (no subjects)

These categories were based on the width of the indicated neutral temperature range and the median of this range (Fig. 10). According to the PMV-model [11], neutral ambient temperature ranges from $21.70{ }^{\circ} \mathrm{C}$ to $25.47{ }^{\circ} \mathrm{C}$ given a certain set of boundary conditions (clo $=$ 0.68 , activity level $=70 \mathrm{~W} / \mathrm{m}^{2}$, air velocity $=0.05 \mathrm{~m} / \mathrm{s}$, relative humidity $=51.6 \%$ ). We defined the categories as follows; subjects in the broad range preference category were those who had a broader indicated neutral temperature range; small range preference subjects had a smaller indicated temperature range. When the median was lower than $21.70{ }^{\circ} \mathrm{C}$, the subject had a preference for cool environments and if it was higher than $25.47^{\circ} \mathrm{C}$, the subject had a preference for warm environments. Between the categories, body composition did not differ significantly.

These categories were used to study the prediction of thermal sensation. Despite the smaller number of subjects included in each analysis, there was an improvement in the relation between wrist skin temperature and thermal sensation for the small range preference subjects $\left(R^{2}=0.687\right.$ compared to $R^{2}=0.558$ for the whole group, both $\mathrm{P}<0.001$; Fig. 9). This improvement was not seen for the broad range preference subjects $\left(R^{2}=0.537, P<0.001\right)$. The multiple regression prediction of thermal sensation by skin temperature of the head, underarm, chest and wrist improved for both categories $\left(R^{2}=0.738\right.$ for the narrow range preference group and $\mathrm{R}^{2}=0.669$ for the broad range preference group compared to $\mathrm{R}^{2}=0.606$ for the whole group, all $\mathrm{P}<0.001)$. Therefore, when categories were used, a better correlation was found between physiological parameters and thermal sensation and thus possibly a better prediction of thermoregulatory behavior from thermal sensation and the physiological parameters can be made.

\section{Discussion}

In this study physiological responses, thermal comfort, thermal sensation, thermal preference and their relation to thermoregulatory behavior were studied. Subjects were exposed to two dynamic protocols: a gradual increase $(+4 \mathrm{~K} / \mathrm{h})$ and a gradual decrease in ambient temperature $(-4 \mathrm{~K} / \mathrm{h})$. Skin temperatures were significantly related to the 
intention of thermoregulatory behavior. Importantly, the results indicate that categorization of the subjects in at least two classes (narrow ambient temperature range preference, broad ambient temperature range preference) improves these correlations substantially. For reliable and accurate predictions of thermoregulatory behavior in the built environment such a categorization seems to be crucial.

Changes in mean, distal and proximal skin temperatures are correlated with changes in thermal sensation and comfort. The highest correlation was seen with wrist skin temperature and thermal sensation $(\mathrm{r}=0.751, \mathrm{P}<0.001)$. Finger skin temperature also correlated with thermal sensation $(r=0.726, P<0.001)$. Wang et al. [14] found a high correlation between finger temperature or finger-forearm temperature gradient and thermal sensation (respectively $\mathrm{r}=0.78$ and $\mathrm{r}=$ 0.80 ). In this study a similar correlation was found between finger temperature and thermal sensation $(r=0.73)$. The range of ambient temperatures was nearly the same in both studies, ranging from $17{ }^{\circ} \mathrm{C}$ to $31{ }^{\circ} \mathrm{C}$ in the study of Wang et al. [14] and $16{ }^{\circ} \mathrm{C}$ to $32{ }^{\circ} \mathrm{C}$ in this study. However, Wang et al. studied their subjects in uniform, steady state conditions at $31^{\circ} \mathrm{C}, 28.2{ }^{\circ} \mathrm{C}, 25.5^{\circ} \mathrm{C}, 19^{\circ} \mathrm{C}$ and $17{ }^{\circ} \mathrm{C}$ and this study was performed with temperature drifts ranging from $24{ }^{\circ} \mathrm{C}$ to $32{ }^{\circ} \mathrm{C}$ and from $24{ }^{\circ} \mathrm{C}$ to $16{ }^{\circ} \mathrm{C}$. Not only finger temperature is correlated to thermal sensation, but also several other skin temperatures are. Schellen et al. [23] found in females that skin temperatures from the hands, forearms and upper arms were significantly related to thermal sensation. Contrary, Zhang et al. [31] observed that body parts such as the back and the chest are dominant in their influence on thermal sensation compared to the hand and the foot. According to our study skin temperatures at several sites were correlated with thermal sensation. The relation between thermal sensation based on the skin temperatures of the head, underarm, chest and wrist is in line with the abovementioned studies. The improvement in predictive value from using only the skin temperature of the wrist $\left(\mathrm{R}^{2}=0.558\right)$ to using four sites $\left(\mathrm{R}^{2}=0.606\right)$ is trivial and probably of no practical significance. In the context of the built environment, such as individual controlled climate systems, monitoring distal skin temperatures such as the wrist instead of proximal sites is of much greater applicability.

Interestingly, with respect to whole body thermal sensation, our results reveal a larger discomfort in the upward ramp (A) in comparison to the downward ramp (B). Other studies show that subjects are more sensitive to colder temperatures and often prefer temperatures higher than neutral [32]. However, in a study by Schellen et al. [33] no differences in thermal comfort were found between the upward and the downward ramp. Although the difference is significant, the difference is relatively small $(-0.04$ vs. -0.62 scale units) and fits within the comfort boundaries as defined in the standards.

In addition to the correlation of physiological parameters with thermal sensation, our results showed that thermal sensation was correlated with thermal preference (Fig. 10). In this research thermal preference was assumed to be an indicator of the intention of thermoregulatory behavior. The requested change, another indicator of the intention of thermoregulatory behavior corresponded to the limits set in the built environment according to the PMV-model (thermal sensation boundaries between -0.5 and 0.5$)[11,12]$. That is, the majority of the cases that preferred no change of the thermal environment were within these boundaries (Fig. 8). The two indicators of the intention of thermoregulatory behavior, thermal preference and the requested change, are highly correlated to thermal sensation. Thus, predicting thermal sensation from several physiological parameters, i.e. head, underarm, chest and wrist skin temperature, gives an indication about the intention of thermoregulatory behavior. This has great potential in the built environment to enable the development of innovative monitoring and control techniques.

Nevertheless, it is debatable if thermal sensation, thermal preference and the behavioral intention would reflect thermoregulatory behavior, as the subjects during our experiments perceived no actual control over the environment. From other studies it is known that both satisfaction and thermal comfort seem to be influenced by occupant's perceived control over the surrounding environment [34]. Further research is necessary to examine whether changes in the before mentioned physiological parameters lead to actual changes in thermoregulatory behavior.

This research extends to the current view on differences between sexes in thermal perception and therefore thermoregulatory behavior [20-24] by adding categories (narrow range preference, broad range preference) within a subpopulation. Our study indicates that when categorization was used, the correlation of the physiological parameters with thermal sensation improved. Only one cool preference subject and no warm preference subjects were found in this study. Nevertheless in other thermal conditions, such as more extreme temperatures, these categories can be important. For example Luck and Wakeling already indicated "warm-preference subjects" in their study, but no further notion was given to this observation [35]. Every category seems to exert different thermoregulatory behaviors and this could lead to a different energy use in a dwelling. Secondly, other subjectgroups such as males and elderly, or subjects with different levels of cold/heat acclimatization are expected to show different responses. This is subject for future investigation. Nevertheless, in designing indoor climate systems the knowledge on categories can be used for the development of (individual controlled) heating or cooling systems. To make more realistic predictions of the energy use of these buildings, categorization can also be useful. Moreover, addressing the category or individual needs in heating and cooling systems may lead to a reduction of the energy use in buildings [38].

Van Marken Lichtenbelt et al. [36] described inter-individual differences in the thermoregulatory responses to cold, linked to age, the composition of the body and sex. Body composition is an important factor in differences in thermoregulatory response. In this study body composition did not significantly differ between the categories. Therefore, body composition cannot explain the difference in the thermoregulatory response between the different categories. In this research female subjects were consciously chosen as the study population, as they express thermal dissatisfaction more often and seem to be more thermal sensitive than males [21-24,37]. In other groups or for comparison between groups body composition may explain differences in thermal response. Thyroid hormone concentrations, which are involved in thermoregulation, were within normal range. It is therefore unlikely that differences in thyroid status can explain the differences between categories. Plasma norepinephrine levels did not change during protocol A and increased during protocol B. This change was the same for both categories and in line with other research [38]. This could also not explain the differences between categories either.

A possible explanation for the existence of categories can be differences in acclimatization [39]. This can affect both the thermoneutral zone (TNZ) and the thermal comfort zone (TCZ). The TNZ is defined as the range of ambient temperatures without regulatory changes in metabolic heat production or evaporative heat loss. The TCZ is defined as the range of ambient temperatures that is experienced as comfortable. For the TCZ, indications exist that the ambient temperature range wherein a subject is feeling thermally comfortable is larger compared to the TNZ [40]. In future research it is important to determine the boundaries of both the TNZ and the TCZ for the different categories, i.e. narrow range preference, broad range preference, cool preference and warm preference. Using categories can be helpful to make more realistic predictions of the energy use of buildings. Furthermore, it would be interesting to examine the existence of these categories in different groups of humans, e.g. in lean and obese. This will lead to better predictions of energy use and realistic calculations of energy consumption in the built environment.

\section{Acknowledgments}

The authors would like to thank the literature club for fruitful discussions. Furthermore, they want to express their gratitude to Paul 
Schoffelen and Loek Wouters for their assistance. This study was supported by AgentschapNL (EOS-LT 10033 project INTEWON).

\section{References}

[1] Branco G, Lachal B, Gallinelli P, Weber W. Predicted versus observed heat consumption of a low energy multifamily complex in Switzerland based on long-term experimental data. Energy Build 2004;36:543-55.

[2] Haas R, Auer H, Biermayr P. The impact of consumer behavior on residential energy demand for space heating. Energy Build 1998;27(2):195-205.

[3] Hirst E, Goeltz R. Comparison of actual energy savings with audit predictions for homes in the north central region of the USA. Build Environ 1985;20(1):1-6.

[4] Santin OG, Itard L, Visscher H. The effect of occupancy and building characteristics on energy use for space and water heating in Dutch residential stock. Energy Build 2009;41(11):1223-32.

[5] Papakostas K, Sotiropoulos B. Occupational and energy behaviour patterns in Greek residences. Energy Build 1997;26(2):207-13.

[6] Benzinger TH. Heat regulation: homeostasis of central temperature in man. Physiol Rev 1969;49(4):671-759.

[7] Cabanac M. Peripheral heat as a reward for heart rate response in the curarized rat. J Comp Physiol Psychol 1976;90(5):435-41.

[8] Schlader ZJ, Simmons SE, Stannard SR, Mundel T. The independent roles of temperature and thermal perception in the control of human thermoregulatory behavior. Physiol Behav 2011;103(2):217-24.

[9] Gagge A, Stolwijk J, Hardy J. Comfort and thermal sensations and associated physiological responses at various ambient temperatures. Environ Res 1967;1(1):1-20.

[10] Nakamura M, Yoda T, Crawshaw LI, Yasuhara S, Saito Y, Kasuga M, et al. Regiona differences in temperature sensation and thermal comfort in humans. J Appl Physiol 2008;105(6):1897-906.

[11] ASHRAE. Standard 55: thermal environmental conditions for human occupancy Atlanta: American Society of Heating. Refrigerating and Air-Conditioning Engineers, Inc.; 2010

[12] Fanger PO. Thermal comfort. New York: McGraw Hill Book Company; 1970.

[13] Marks LE, Gonzalez RR. Skin temperature modifies the pleasantness of thermal stimuli. Nature 1974;247(441):473-5.

[14] Wang D. Observations of upper-extremity skin temperature and corresponding overall-body thermal sensations and comfort Build Environ 2007:42(12):3933-43.

[15] Chatonnet J, Cabanac M. The perception of thermal comfort. Int J Biometeorol 1965;9(2):183-93.

[16] Zhang H. Human thermal sensation and comfort in transient and non-uniform thermal environments. Berkeley: University of California; 2003.

[17] Zhang H, Arens E, Huizenga C, Han T. Thermal sensation and comfort models for non-uniform and transient environments, part III: whole-body sensation and comfort. Build Environ 2010;45(2):399-410.

[18] Song GS, Lim JH, Ahn TK. Air conditioner operation behaviour based on students' skin temperature in a classroom. Appl Ergon 2012;43(1):211-6.

[19] Schlader ZJ, Perry BG, Jusoh MR, Hodges LD, Stannard SR, Mundel T. Human temperature regulation when given the opportunity to behave. Eur J Appl Physio 2012;113(5):1291-301

[20] Cena K, de Dear R. Thermal comfort and behavioural strategies in office buildings located in a hot-arid climate. J Therm Biol 2001;26(4-5):409-14.
[21] Karjalainen S. Thermal comfort and gender: a literature review. Indoor Air 2012;22(2):96-102.

[22] Kingma B, Frijns A, van Marken Lichtenbelt W. The thermoneutral zone: implications for metabolic studies. Front Biosci, 4, Elite ed.; 2012. p. 1975-85.

[23] Schellen L, Loomans MG, de Wit MH, Olesen BW, van Marken Lichtenbelt WD. The influence of local effects on thermal sensation under non-uniform environmental conditions-gender differences in thermophysiology, thermal comfort and productivity during convective and radiant cooling. Physiol Behav 2012;107(2): 252-61.

[24] Pellerin N, Candas V. Combined effects of temperature and noise on human discomfort. Physiol Behav 2003;78(1):99-106.

[25] Baker FC, Waner JI, Vieira EF, Taylor SR, Driver HS, Mitchell D. Sleep and 24 hour body temperatures: a comparison in young men, naturally cycling women and women taking hormonal contraceptives. J Physiol 2001;530(Pt 3):565-74.

[26] Baker FC, Mitchell D, Driver HS. Oral contraceptives alter sleep and raise body temperature in young women. Pflugers Arch 2001;442(5):729-37.

[27] Harris JA, Benedict FG. A biometric study of basal metabolism in man. Washington: Carnegie Institution of Washington; 1919.

[28] EN-ISO 7730. Ergonomics of the thermal environment - analytical determination and interpretation of thermal comfort using calculation of the PMV and PPD indices and local thermal comfort criteria. Geneva: International Standards Organization; 2005.

[29] EN-ISO 9886. Ergonomics - evaluation of thermal strain by physiological measurements. Geneva: International Standards Organization; 2004.

[30] EN-ISO 10551. Ergonomics of the thermal environment - assessment of the influence of the thermal environment using subjective judgement scales. Geneva: International Standards Organization; 2001.

[31] Zhang H, Huizenga C, Arens E, Wang D. Thermal sensation and comfort in transient non-uniform thermal environments. Eur J Appl Physiol 2004;92(6):728-33.

[32] van Hoof J. Forty years of Fanger's model of thermal comfort: comfort for all? Indoor Air 2008;18(3):182-201.

[33] Schellen L, van Marken Lichtenbelt WD, Loomans MGLC, Toftum J, de Wit MH. Differences between young adults and elderly in thermal comfort, productivity, and thermal physiology in response to a moderate temperature drift and a steadystate condition. Indoor Air 2010;20(4):273-83.

[34] Paciuk M. The role of personal control of the environment in thermal comfort and satisfaction at the workplace. 21th Annual Conference of the Environmental Design Research Association; Champaign-Urbana; 1990.

[35] Luck P, Wakeling A. Set-point displacement for behavioural thermoregulation in anorexia nervosa. Clin Sci 1982:62:677-82.

[36] van Marken Lichtenbelt W, Frijns A, Fiala D, Janssen F, Van Ooijen A, Van Steenhoven A. Effect of individual characteristics on a mathematical model of human thermoregulation. J Therm Biol 2004;29(7):577-81.

[37] Cena K, de Dear R. Thermal comfort and behavioural strategies in office buildings located in a hot-arid climate. J Therm Biol 2001;26(4-5):409-14.

[38] Celi FS, Brychta RJ, Linderman JD, Butler PW, Alberobello AT, Smith S, et al. Minimal changes in environmental temperature result in a significant increase in energy expenditure and changes in the hormonal homeostasis in healthy adults. Eur J Endocrinol 2010;163(6):863-72.

[39] Davis TR. Chamber cold acclimatization in man. J Appl Physiol 1961;16:1011-5 [Epub 1961/11/01].

[40] van Marken Lichtenbelt WD, Kingma BR. Building and occupant energetics: a physiological hypothesis. Archit Sci Rev 2013;56(1):48-53. 